\title{
The extracellular matrix in the kidney: a source of novel non-invasive biomarkers of kidney fibrosis?
}

\author{
Federica Genovese ${ }^{1 *}$, Alba A Manresa ${ }^{1}$, Diana Julie Leeming ${ }^{1}$, Morten Asser Karsdal ${ }^{1}$ and Peter Boor ${ }^{2,3,4^{*}}$
}

\begin{abstract}
Interstitial fibrosis is the common endpoint of end-stage chronic kidney disease (CKD) leading to kidney failure. The clinical course of many renal diseases, and thereby of CKD, is highly variable. One of the major challenges in deciding which treatment approach is best suited for a patient but also in the development of new treatments is the lack of markers able to identify and stratify patients with stable versus progressive disease. At the moment renal biopsy is the only means of diagnosing renal interstitial fibrosis. Novel biomarkers should improve diagnosis of a disease, estimate its prognosis and assess the response to treatment, all in a non-invasive manner. Existing markers of CKD do not fully and specifically address these requirements and in particular do not specifically reflect renal fibrosis. The aim of this review is to give an insight of the involvement of the extracellular matrix (ECM) proteins in kidney diseases and as a source of potential novel biomarkers of renal fibrosis. In particular the use of the protein fingerprint technology, that identifies neo-epitopes of ECM proteins generated by proteolytic cleavage by proteases or other post-translational modifications, might identify such novel biomarkers of renal fibrosis.
\end{abstract}

Keywords: Kidney fibrosis, Biomarkers, Extracellular matrix, Matrix metalloproteinases

\section{Review}

Renal fibrosis is the principal pathological process underlying the progression of chronic kidney disease (CKD) and finally leading to end-stage renal disease (ESRD). For patients progressing to ESRD the mortality levels exceed those of some malignancies. This devastating condition is not only a major problem for the lives of patients, but also an economic burden for the health system.. The US Renal Data System, USRDS 2013 Annual Data Report estimated that $14 \%$ of the adult population in the USA had CKD and the costs for CKD patients older than 65 reached over $\$ 45$ billion [1]. Patients with ESRD require lifelong dialysis and the only possible treatment is kidney transplant.

Renal and in particular interstitial fibrosis is a common feature of CKD, regardless of the etiology of the primary disease. Interstitial fibrosis is the strongest indicator of disease progression, even when the primary disease is of glomerular origin [2]. Therapies for renal fibrosis with proven efficacy in clinical settings currently do not exist. The challenge in finding anti-fibrotic therapies is partly

\footnotetext{
* Correspondence: fge@nordicbioscience.com; pboor@ukaachen.de ${ }^{1}$ Nordic Bioscience, 2730 Herlev, Denmark

${ }^{2}$ Nephrology and Immunology, RWTH Aachen University, Aachen, North Rhine-Westphalia, Germany

Full list of author information is available at the end of the article
}

due to the need of long and expensive clinical trials, as the currently used clinical endpoints require long study durations and a large number of patients [3]. The development of novel, non-invasive, fibrosis-specific biomarkers, reflecting morphological tissue changes at early stages and predicting the evolution of renal fibrosis, would be of great importance. Such biomarkers would facilitate clinical studies with experimentally established drugs targeting profibrotic molecules and could identify patients that need to be treated at the right moment.

The PubMed database was searched to identify articles on renal fibrosis using the following keywords: renal fibrosis, extracellular matrix (ECM), CKD, biomarkers, collagen, proteoglycans, glomerular basement membrane, mesangium and matrix metalloproteinase (MMP), as Medical Subject Headings (MeSH). The reference lists of identified papers were also used for further search. Each author further selected key publications based on their personal knowledge on the topic of biomarkers for renal fibrosis. Only full-text articles written in English were included and the focus was placed on studies published within the last three years. 


\section{Mechanisms of renal fibrosis}

Renal fibrosis, that is, the accumulation and dysregulated remodelling of ECM, can affect all major compartments of the kidney being termed glomerulosclerosis in the glomeruli, tubulointerstitial fibrosis in the tubulointerstitium and arterio- and arteriolosclerosis in the vasculature. At a certain point, virtually all renal cells are involved in fibrosis [4]. The description of the cellular and molecular mechanisms of kidney fibrosis is beyond the scope of this review and has already been thoroughly discussed by others [5-7]. We will focus on the mechanisms related to ECM accumulation and remodelling in renal fibrosis as a potentially relevant source of novel biomarkers for renal fibrosis.
Renal fibrosis is the result of a failed wound healing process that occurs after an initial insult. The pathophysiology of renal fibrosis can be divided into four phases: 1) cellular activation and injury phase or priming; 2) fibrogenic signalling phase or activation; 3) fibrogenic phase or execution; and 4) destructive phase or progression. Figure 1 describes the different phases of tubular interstitial fibrosis and some of the cells and molecules that intervene in the process. These phases can be best studied and differentiated in animal models, in which a disease stimulus is often applied at a single time-point so that the injury and the progression are synchronized. In most, if not all, human diseases this is not the case and, to a variable and yet not defined extent, all phases can be

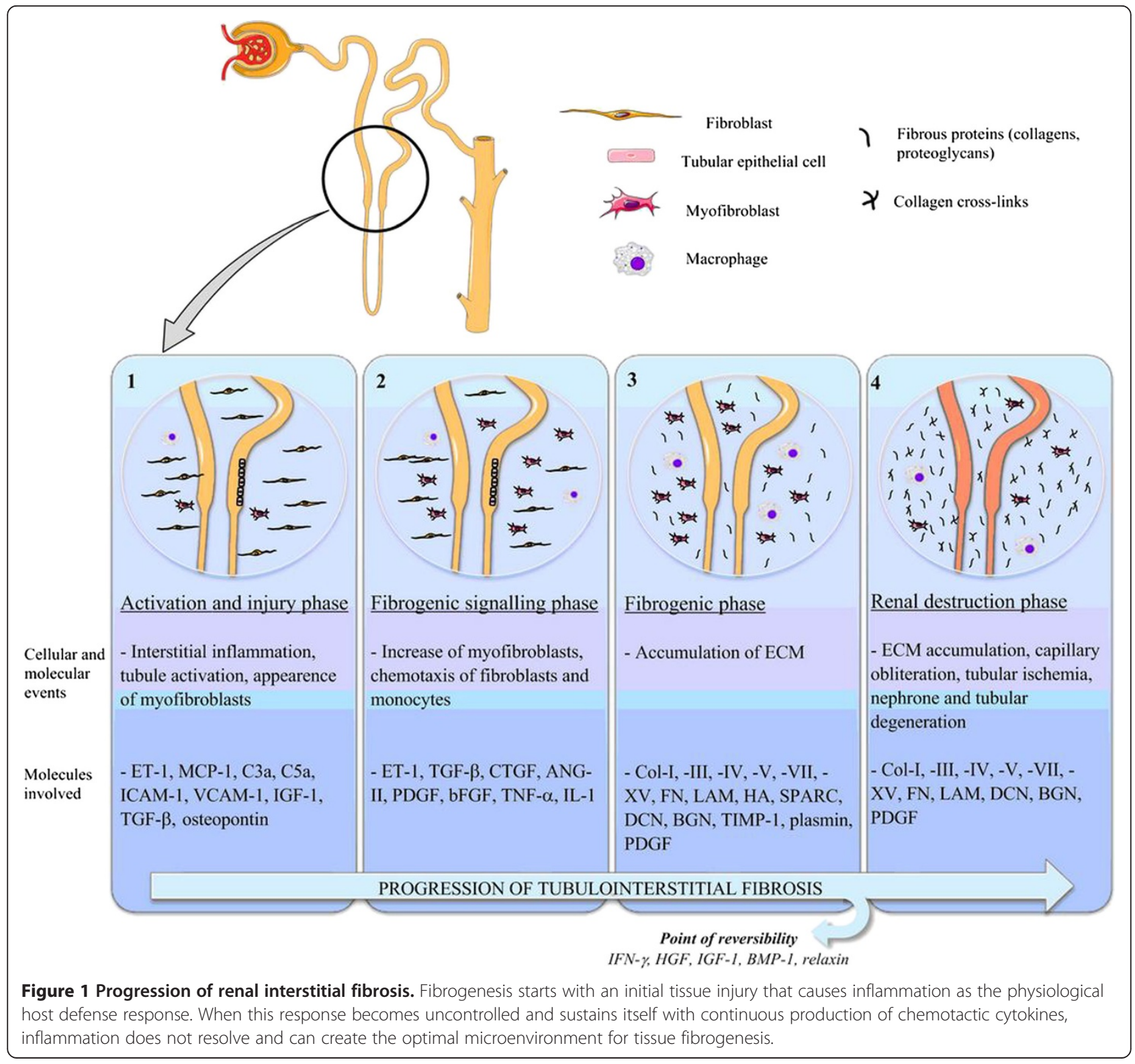


observed at the same time. Various mediators of renal fibrosis have been described, such as the prototypical profibrotic molecules transforming growth factor beta 1 (TGF- 11 ) and platelet-derived growth factor (PDGF), which will not be discussed in detail here $[8,9]$. Among the effectors causing a pathological matrix accumulation, plasminogen activator inhibitor-1 (PAI-1), which is induced by TGF- $\beta$, was shown to modulate fibrosis via effects on cell migration, matrix turnover and macrophage infiltration [10]. The role of this effector in kidney fibrosis has been described elsewhere [11]. Even though many cell types in the kidney are able to produce ECM, (myo-) fibroblasts in the interstitium and mesangial cells in the glomeruli are considered the main cellular mediators of interstitial fibrosis and glomerulosclerosis, respectively $[2,12]$. In the kidney, myofibroblasts can originate from different sources, the most important being resident interstitial fibroblasts in the cortex and pericytes in the medulla. Other sources seem to contribute to a lesser and varying extent to the pool of myofibroblasts and include endothelial cells (via endothelial-to-mesenchymal transition), tubular epithelial cells (via epithelial-tomesenchymal transition) and fibrocytes [2,12,13].

Fibronectin is the first ECM protein that is deposited in fibrogenesis [14]. It activates integrins, functions as a fibroblast chemoattractant and co-localizes with collagen formation. This triggers the production of a large variety of ECM proteins, discussed below [7]. The synthesis, deposition and degradation of different ECM proteins, their post-translational modifications, together with the induction of proteases and protease inhibitors and other ECM remodelling enzymes (for example tissue transglutaminase) contribute to the development of irreversible fibrosis [7].

\section{Diagnosis of renal fibrosis}

At present, kidney biopsy is the only method to detect renal fibrosis. It is an invasive procedure with possible complications. The extent of interstitial fibrosis in kidney biopsy is most often reported in a semi-quantitative manner and has several intrinsic limitations, mainly due to sampling error and to intra- and inter-observer variability [15]. Imaging techniques, such as ultrasound, can show signs of corticomedullary differentiation, which is a sensitive but not specific marker of CKD; it can moreover show the size of the kidneys, the presence of cysts and solid lesions, urinary obstruction or scars but it cannot diagnose the presence of ongoing interstitial or glomerular fibrogenesis [16]. Another imaging technique that is attracting increasing interest is the magnetic resonance elastography (MRE), already used in the hepatic field to detect liver fibrosis [17]. MRE can non-invasively sample tissue stiffness in vivo, and its possible use in renal fibrosis is under evaluation [18]. At the moment, there are no specific molecular imaging modalities for renal fibrosis.

Serological and urinary markers can rapidly change following a physiological or pathological event, and are therefore dynamic. Here we will discuss established, developing and potential serological and urinary markers of renal fibrosis.

\section{Chronic kidney disease (CKD) biomarkers}

In the last decade, there has been intense interest and effort in finding novel predictive biomarkers for the diagnosis and prognosis of CKD. Several molecules involved in kidney function, signalling and structure have been evaluated as potential markers for CKD [19]. The only markers currently accepted and used in clinical practice for the diagnosis and prognosis of CKD are markers of loss of kidney function. The most widely used are the estimated glomerular filtration rate (eGFR) [20], serum creatinine, blood urea nitrogen (BUN) [21] and albuminuria or proteinuria [22]. Cystatin C [23] and $\beta$-trace protein [24] have been proposed as an alternative to creatinine to estimate the GFR. These markers indicate impaired renal function but have no disease specificity, and detectable changes in their concentration come after the biological changes in the organ causing the functional impairment.

Molecules involved in inflammation or in signalling leading to the onset of fibrosis have been studied as possible markers for renal fibrosis. Some of these molecules belong to the panel of urinary biomarkers proposed by the Predictive Safety Testing Consortium (PSTC) for the detection of drug-induced kidney toxicity [25]. Even though the purpose of these markers is to detect an acute response to the injury, some are also being evaluated as early markers of CKD and progression towards ESRD. These molecules include: C-reactive protein (CRP), tumor necrosis factor receptor II (TNFRII), TGF- $\beta 1$ and pentraxin-3 as cytokines involved in the development of CKD; asymmetric dimethylarginine (ADMA) as a marker of endothelial dysfunction and consequent kidney damage [26]; fibroblast growth factor-23 (FGF-23), adiponectin and apolipoprotein A-IV as metabolic factors involved in the regulation of kidney metabolism; and gamma-glutamyl transpeptidase (GGT) as molecules involved in oxidative stress, which can contribute to CKD pathogenesis. Endostatin, the N-terminal portion of collagen type XVIII, is a potent anti-angiogenic factor which has been recently evaluated as a marker of CKD. A significant elevation of endostatin in plasma of patients with CKD following disease severity compared to controls without CKD was observed [27]. Except FGF-23, all the other markers are not kidney-specific and require further evaluation in larger clinical cohorts to confirm their potential (reviewed thoroughly elsewhere [19]). FGF-23 
is currently one of the most promising markers for CKD. This phosphaturic hormone is increased in serum in a physiological adaptation to the hyperphosphatemia that arises when the GFR decreases below $25 \mathrm{ml} / \mathrm{min} /$ $1.73 \mathrm{~m}^{2}$ [28]. Several studies demonstrated the potential of FGF-23 as a marker of mortality in dialysis patients [29], initiation of chronic dialysis [30], CKD progression [31,32], cardiovascular disease [30], cardiovascular mortality [32] or all-cause mortality [30,32].

Kidney-specific molecules are more likely to specifically reflect renal injury. Such molecules include podocytespecific proteins nephrin, podocin and podocalyxin as urinary markers of glomerular damage [33,34]. Following the same rationale, neutrophil gelatinase-associated lipocalin (NGAL) [35], kidney injury molecule-1 (KIM-1) [36,37], $\mathrm{N}$-acetyl-beta-D-glucosaminidase (NAG) and liver-type fatty acid-binding protein (L-FABP) [38-41] can be markers of tubular damage, as these are proteins expressed in the tubules that can be released in serum or urine following tubular damage. Both NGAL and KIM-1 are well-known markers of acute kidney injury and their potential as diagnostic and prognostic markers of CKD has been evaluated in various studies and reviewed in detail elsewhere [19]. NGAL was shown to be increased in serum and/or urine of patients suffering from different kidney diseases, for example in patients with IgA nephropathy (IgAN), various glomerulonephritis, autosomal dominant polycystic kidney disease (ADPKD), pediatric lupus nephritis and CKD from a range of etiologies, and to differentiate between CKD stages [19,42]. NGAL might be a good marker for tubulointerstitial injury in CKD, and might identify progression of the disease. It has to be mentioned though, that the results are not consistent in all studies $[35,43,44]$. Urinary KIM-1 levels were associated with the outcome of incident CKD or rapidly declining kidney function in the Multi-Ethnic Study of Atherosclerosis (MESA) cohort [44]. Other studies $[41,43,44]$ showed a good potential for KIM-1 as a diagnostic marker for CKD and even as a marker of efficacy of intervention. However, as for many other markers, confirmation in long-term observational studies using larger populations is still required $[19,43]$. First hints suggest that cytokeratin 18, which can be released into urine and circulation following renal epithelial cell death, might also be a novel marker of CKD. Serological and urinary concentration levels of total cytokeratin 18 measured in CKD patients could separate patients with advanced CKD from patients with mild disease and healthy controls [45]. All these molecules have been evaluated for their association with impaired kidney function, but they are not directly linked to fibrosis, that is, to the deposition and remodelling of ECM. The tubular damage markers are not completely specific for the kidneys, as many of these proteins are also involved in other diseases, as for example NGAL (also known as lipocalin-2) in the liver.
In the search for specific biomarkers of kidney fibrosis, the ECM proteome is a large source of new potential targets. Only a few of these proteins have been analyzed as diagnostic and prognostic markers, despite their involvement in renal fibrosis that has been proven. A good biomarker should reflect the presence of renal fibrosis and be linked to an outcome (decline in eGFR, renal failure, death). The ideal biomarker should be detected non-invasively and should be able to predict the progression of the disease and/or the response to a treatment in a more sensitive and specific manner compared to standard parameters.

The following sections give an overview on involvement of renal ECM proteins and proteases in renal fibrosis and their potential utility as diagnostic or prognostic markers of renal fibrosis.

\section{The extracellular matrix (ECM) of the kidney}

The ECM is a very dynamic, highly charged structure which acts both as a support structure for the cells and as an active component in cell signalling [46]. It is composed of collagens, glycoproteins and elastin molecules which form a complex network interacting with each other and with the surrounding cells. Proteases, for example MMPs and their inhibitors, are responsible for maintaining the equilibrium between formation and degradation of ECM proteins. In the kidney cortex, the ECM is present in anatomically distinct areas with different functions depending on its molecular components:

1. in the glomeruli
a. glomerular basement membrane
b. Bowman's capsule
c. mesangial ECM

2. in the tubulointerstitium

a. tubular basement membrane (in part segmentspecific)

b. peritubular capillary basement membrane

c. interstitial ECM

3. in larger vessels
a. within the vessels (lamina elastica interna and externa)
b. around the vessels (adventitia of arteries and veins)

Medullary interstitial ECM is physiologically more prominent compared to the cortical interstitial ECM, steadily increasing in quantity in the direction from outer to inner medulla/papilla. The functional consequence of this difference is yet unclear. The hilar region, renal pelvis (for example suburothelial basement membrane) and renal capsule are also composed of ECM. The contribution and remodelling of ECM in these specific anatomical locations in renal fibrosis are not well-studied. 
The next paragraphs describe the proteins that compose the renal ECM in healthy state and those involved in the onset of fibrosis, with particular focus on those that can be a source of new biomarkers. A comprehensive list of experimental evidence for ECM proteins being involved in renal fibrosis, derived from both pre-clinical and clinical studies, is included in Additional file 1: Table S1.

\section{Glomerular basement membrane (GBM)}

The glomerular basement membrane (GBM) is thicker compared to most other basement membranes. It contains four main macromolecules: laminin, collagen type IV, nidogen and heparan sulphate proteoglycans. The main function of the GBM is to act as a charge- and sizeselective filtration barrier between the vascular system and the urinary space.

Laminin is secreted as an $\alpha \beta \gamma$ heterotrimer $(\alpha 5, \beta 2$ and $\gamma 1$ laminins are present in the mature GBM [47]), which forms a network required to maintain the basement membrane integrity. Mutations of the laminin genes can lead to kidney diseases, for example mice with a hypomorphic mutation in the gene for the laminin $\alpha 5$ subunit develop polycystic kidney disease [48]; a null mutation of the gene for the laminin $\alpha 4$ subunit can cause progressive glomerular and tubulointerstitial fibrosis [49]; and truncation or severe missense mutations in the gene for the laminin $\beta 2$ subunit can cause Pierson syndrome, characterized by premature death from renal failure [47].

Collagen type IV is composed by three $\alpha$ chains that fold in a triple helix and, by binding with other collagen type IV molecules, form the meshwork conformation typical of the basement membrane. The $\alpha 3$ (IV), $\alpha 4$ (IV) and $\alpha 5$ (IV) chains are the most expressed in the adult GBM [50]. Mutations in the gene for the $\alpha 5$ chain of collagen type IV cause the X-linked Alport syndrome in humans, a rare genetic disease characterized by progressive glomerular injury. Mutations in the genes for the $\alpha 3$ and $\alpha 4$ chains can cause autosomal recessive and autosomal dominant Alport syndrome and thin basement membrane nephropathy. Collagen type IV is also the target of two autoimmune diseases affecting the kidney: Goodpasture's syndrome and Alport post-transplantation disease. Both diseases are characterized by autoantibodies attacking the GBM and causing rapidly progressive glomerulonephritis [47]. Knock-out mice for the gene for the $\alpha 3$ chain and for the $\alpha 5$ chain of collagen type IV are widely used as murine models of autosomal and X-linked Alport syndrome, respectively [51,52]. Increased collagen type IV expression was described in chronic transplant nephropathy using immunohistochemistry [53]. The distribution of up-regulated collagen type IV was uniform in the GBM, in the mesangium and in the interstitium. Collagen type IV was also used in experimental animal studies as a marker of glomerular sclerosis and interstitial fibrosis $[8,54]$.

Elevated urinary concentration levels of collagen type IV have been associated with the decline of renal function in patients with type 1 [55] and type 2 diabetes [56,57], but also in non-diabetic nephropathies, such as membranous nephropathy and anti-neutrophil cytoplasmic antibody (ANCA)-associated glomerulonephritis [58]. Specifically, type 1 diabetic nephropathy (DN) patients with elevated urinary collagen type IV to creatinine ratio (T4C) but normal albumin to creatinine ratio (ACR) declined more rapidly in eGFR than patients with normal T4C [55]. In type 2 diabetic patients, increased collagen type IV urine excretion was associated with the severity of morphological alterations in fibrosis, albeit no direct relationship with the content of collagen type IV in the kidney could be observed [56]. Another study in type 2 diabetic patients with normoalbuminuria and microalbuminuria found an inverse correlation between urinary collagen type IV excretion and the outcome annual decline of eGFR, but no correlation with progression to advanced diabetic nephropathy was found [57]. In a study on biopsy-proven membranous nephropathy and ANCA-associated glomerulonephritis [58] elevated levels of urinary collagen type IV were correlated with urinary proteins, urinary NAG and selectivity index. Different results were observed in a urinary peptidome study performed in type I diabetic patients. Patients with progressive early function decline showed a decreased expression of fragments of collagen type IV ( $\alpha 1$ chain) compared with control subjects with stable renal function [59]. These results suggest that urinary collagen type IV might be a promising additive biomarker in patients with diabetic nephropathy and further clinical studies are eagerly awaited.

The transmembrane collagen type XVII has been recently identified in the GBM. Its deficiency causes effacement of podocyte foot processes, therefore it might be involved in the attachment of the podocyte to the GBM [60]. Nidogen 1 and 2 bind to collagen type IV and laminin separately. Although nidogens have a role in the basement membrane formation, experimental evidence showed that they are not strictly required for GBM formation [61]. Agrin is the major heparan sulphate proteoglycan of the GBM in healthy kidneys, while perlecan is an abundant component of other basement membranes [62]. Perlecan expression levels are increased in the glomeruli of IgAN patients and correlate with a lower urinary albumin excretion, suggesting that perlecan could be a marker of slower progression of the disease, and therefore of better outcome [63]. Perlecan and agrin, as all the heparan sulphate proteoglycans, have highly negatively charged glycosaminoglycans (GAGs), assumed to contribute to the negative charge of the basement membrane [61]. Interestingly, 
several studies showed that lack of perlecan and agrin does not lead to proteinuria, even though it affects the negative charge of the GBM [64-66].

\section{Mesangial ECM}

The mesangial ECM provides structural support for the glomerular capillary convolute, connecting with the extraglomerular mesangium at the vascular pole. It has a role in cell-matrix signalling in a bidirectional manner. Dysregulation of this cell-matrix signalling plays a role in a wide range of glomerular diseases [67], such as IgAN [68] and DN [69]. Mesangial ECM differs substantially from GBM, and its composition allows larger molecules to pass to the mesangium. In physiological conditions its major components are fibronectin, collagen type IV ( $\alpha 1$ and $\alpha 2$ chains, but not $\alpha 3$ and $\alpha 5$ ), collagen type $\mathrm{V}$, laminin $\mathrm{A}, \mathrm{B} 1$ and $\mathrm{B} 2$, chondroitin sulphate and heparan sulphate proteoglycans (perlecan, collagen type XVIII and bamacan, but not agrin) and nidogen $[47,67]$. The small proteoglycans decorin, biglycan, fibromodulin and lumican are weakly expressed in the mesangial matrix and rather localized in the tubular interstitium [70]. Under pathological conditions, decorin and biglycan were shown to be up-regulated in glomeruli [63]. Consistently, elevation of collagen type IV was also reported in several studies with humans and rodent models where protein localization and both protein and mRNA levels were assessed [69,71-73].

Typical scar collagen type I is de novo expressed in glomerulosclerosis, and by inhibiting its accumulation, a reduction in the extent of glomerulosclerosis was obtained in a model of $\mathrm{DN}$ [74]. MMPs play an important role in the homeostasis of the mesangial matrix, for example alterations on MMP function were shown to be linked to light chain diseases [75].

At the moment it is unclear whether glomerular ECM (either GBM or mesangium) might provide specific biomarkers of glomerular injury.

\section{Interstitial ECM}

The renal interstitial matrix is normally composed by collagen type I, III, V, VI, VII and XV, both sulphated and non-sulphated glycosaminoglycans, glycoproteins and polysaccharides. During fibrosis, the formation of scar tissue in the interstitial space is the result of the excessive accumulation of ECM components.

\section{Collagens}

Collagens constitute the main structural element of the interstitial ECM, providing tensile strength, regulating cell adhesion, support, chemotaxis, cell migration and tissue development [76]. Collagen type I and III are known to be deposited in early stages during renal fibrosis $[73,77,78]$.
Collagen type I accumulates in fibrotic glomeruli, tubulointerstitial space and arterial walls in pathological conditions, co-localizing with decorin and biglycan [79]. Collagen type I accumulation in fibrosis, as many other ECM molecules, is both due to decreased degradation and elevated synthesis $[14,69]$. Urinary proteome analyses could differentiate DN patients from healthy individuals and patients with other chronic kidney diseases [80]. Among the proteins differentially expressed, fragments of collagen type I were significantly less present in the urine of DN patients. The authors suggested that this indicated a decreased collagen proteolysis, probably due to cross-linking rendering the collagens resistant to proteolytic cleavage or to increased protease inhibitor expression [80].

In physiological conditions collagen type III is normally expressed at low levels in the interstitium, and it is undetectable in glomeruli. However, during fibrosis the expression levels are increased in the interstitium and in the glomeruli, as shown by immunohistochemical analysis on human renal biopsies using antibodies against the collagen type III N-terminal pro-peptide (PIIINP) [81].

PIIINP was detected in high concentrations in urine and serum of patients with various renal diseases [81-83]. Urinary PIIINP (and collagen IV) levels were elevated in patients with various nephropathies and correlated with the extent of interstitial fibrosis in kidney biopsies [81]. The urinary PIIINP to creatinine ratio (uPIIINP/Cr) was evaluated in kidney transplant patients and correlated with the extent of interstitial fibrosis [82]. Furthermore, in another study on patients with different CKD stages subjected to kidney biopsy, uPIIINP/Cr correlated with serum creatinine, eGFR and CKD stage as well as with the extent of fibrosis evaluated in the biopsies [83].

Elevation of collagen type V and VI in kidney fibrotic tissue has been reported in various studies $[69,84]$. Conversely, decreased concentrations of collagen type $\mathrm{V}$ ( $\alpha 1$ chain) were observed in a urinary peptidome of patients with type $1 \mathrm{DN}$ with early renal function decline [59]. Although different types of collagen are highly upregulated in renal fibrosis, so far only PIIINP and collagen type IV have been analyzed as potential biomarkers. Both are among the most promising specific markers reflecting renal fibrosis.

\section{Glycoproteins}

Fibronectin is an adhesive glycoprotein involved in the organization of the ECM. Its accumulation is one of the first events during renal fibrosis [14]. It was shown to be up-regulated in many animal models and in human CKD $[69,71,73,78,85]$.

Thrombospondin-1 (TSP-1) is an adhesive glycoprotein involved in fibroblast proliferation and migration [86]. It was shown to be up-regulated before the disease onset, 
and correlated with the degree of tubulointerstitial fibrosis in three different rat models of renal fibrosis. TSP-1 was observed to be transiently expressed at early fibrosis stages, suggesting a possible role as a mediator of interstitial fibrosis via activation of TGF- $\beta[69,86]$.

Proteoglycans are a subgroup of glycoproteins with a high content of carbohydrates, which fill the majority of the renal extracellular interstitial space. They have a wide variety of functions, such as hydration, force-resistance and growth factor binding [87]. The latter is important in renal fibrosis as proteoglycans act as a reservoir of profibrotic growth factors, such as the latent forms of TGF- $\beta$ or FGF-2 [5].

Decorin, biglycan and fibromodulin are small leucinerich proteoglycans (SLRPs), which act as potent regulators of TGF- $\beta[62,88]$. Decorin and biglycan also have an important role in collagen fibrillogenesis. In healthy adult renal tissue, decorin and biglycan are expressed in the tubulointerstitium and weakly in the glomeruli [69]. However, during progressive renal scarring an increased expression of decorin and biglycan was observed in various experimental models of renal injury and in humans [79,84,85,89-91]. Specifically, in the unilateral ureteral obstruction (UUO) model, tubular biglycan up-regulation was observed before macrophage infiltration, indicating that biglycan could act as an initiator and regulator of inflammation in the kidney [89]. Biglycan and decorin expression was also found to be highly up-regulated in the glomeruli of IgAN patients, indicating a potential role in this glomerular disease [63]. Decorin has wellknown anti-fibrotic properties: it neutralizes TGF- $\beta$ activity by interfering with its signalling; it exerts an anti-apoptotic activity on tubular epithelial and endothelial cells; and can induce fibrillin-1 expression, by binding the insulin-like growth factor type I (IGF-I) receptor [92]. Its use as an anti-fibrotic molecule has been shown in a rat model of glomerulonephritis [93].

Hyaluronan is a high molecular weight glycosaminoglycan formed by the repetition of disaccharides composed by $\mathrm{N}$-acetylglucosamine and glucuronic acid [62]. It has the ability to bind to a variety of proteoglycans and to cell receptors acting as a signalling molecule. In a healthy human kidney, hyaluronan is very little expressed. However, during progressive kidney disease, it accumulates in the cortical interstitium and may potentiate interstitial inflammation by stimulating the recruitment of monocytes to the interstitial space [5]. Elevated levels of hyaluronan in renal tissue were reported in several kidney diseases in both rat models, for example ischemia-reperfusion injury, and human diseases, for example $\mathrm{DN}$, renal transplant rejection and kidney stone formation [94].

Versican is a chondroitin sulphate proteoglycan, the largest member of the modular proteoglycans, with an important role in maintaining the integrity of the ECM by interacting with hyaluronan $[89,95]$. In healthy renal tissue, versican is found expressed in the tubulointerstitium and the blood vessels, but not in the glomeruli [96]. In patients with different proteinuric nephropathies, versican expression was increased in areas with marked tubulointerstitial fibrosis, suggesting that versican may have an important role during CKD progression [97]. Most of the above mentioned glycoproteins undergo significant regulation during kidney fibrosis. Still, no data exist on their potential as renal biomarkers.

\section{Matrix metalloproteinases (MMPs) and other proteases}

The enzymes playing a central role in matrix remodelling are metalloproteinases. Metalloproteinases are synthesized in kidneys and have an important function in maintaining the homeostasis of the ECM. The main families of metalloproteinases are MMPs, a disintegrin and metalloproteinase (ADAM) proteins and a disintegrin and metalloproteinase with thrombospondin motifs (ADAMTS). The role of ADAMs and ADAMTS is only starting to emerge and will not be discussed here [98-103]. Serine proteases (plasmin and cathepsin G) and cysteine proteases (cathepsins B, H and L) can also contribute to the degradation of ECM components at neutral $\mathrm{pH}[104]$.

\section{MMPs and tissue inhibitors of metalloproteinases (TIMPs)}

MMPs are zinc-dependent enzymes involved in ECM remodelling, which play a central role in tissue homeostasis. There are 23 MMPs in humans [105] and at least ten of them are expressed in the kidney (MMP-1, -2, -3, $-9,-13,-14,-24,-25,-27$ and -28) [106]. MMP-12 was thought not to be expressed in the kidney even though some experimental results in an animal model suggest the opposite [107]. MMPs were hypothesized to be antifibrotic due to their function as ECM degradation enzymes. Increasing evidence suggests that MMPs have a more complex role in renal fibrosis $[4,108,109]$. For example, MMP-9-mediated degradation of collagens creates collagen fragments, which possess chemotactic properties for neutrophils and are able to stimulate MMP-9 production. Apart from their action on ECM components, MMPs are also known to modulate growth factors and their receptors (TGF- $\beta$, FGF-R1), adhesion molecules (integrins and cadherins) [109], cytokines and chemokines. Consequently, MMPs are involved in several processes aside from ECM remodelling, such as destruction of the basement membrane, angiogenesis, cell migration and cell apoptosis, some being pro- and some anti-fibrotic depending on the context $[4,109,110]$. MMPs are inhibited permanently by degradation or temporarily by tissue inhibitors of metalloproteinases (TIMPs). A balance between MMP and TIMP activity is essential for ECM homeostasis [109]. Among the four TIMPs that have been identified in vertebrates, TIMP-1, -2 and -3 are 
expressed in the kidney [106]. Increased mRNA and protein levels of TIMP-1 were reported in several human and rodent models of different renal diseases, suggesting that TIMP-1 might be involved in the early events during the progression of renal diseases [5,73,109]. TIMP-2 has also been shown to be elevated in various rat models of renal disease [73]. The exact localization and temporal expression of MMPs in the human kidney is still not completely understood [108]. Most of the data on MMP expression derive from animal models of kidney diseases (Additional file 1: Table S1). MMP-2 and MMP-9 are known to be involved in the proteolysis of collagen type IV, which accumulates in the basement membranes, for example in early stages of DN. MMP-2 and MMP-9 expression and activity were up-regulated in different animal models of renal fibrosis $[69,91,109,111,112]$, but were decreased in cases of DN in both humans and rats $[69,113]$. Changes in MMP-2 and MMP-9 activity might therefore influence the ECM composition causing renal damage at early stages of DN [106]. However, another study showed that urinary levels of MMP-9, together with collagen type IV, were elevated in type $2 \mathrm{DN}$ patients with macroalbuminuria [114]. MMP-3 expression and activity during DN was decreased in both humans and rats [69]. MMP-7 is not expressed in healthy human kidneys but was found in epithelial cells and atrophic tubules in patients with ADPKD and in a mouse model of acute renal tubule injury and chronic progressive renal fibrosis [115]. Some of the contrasting results, particularly in regards to MMP-2 and MMP-9, can be explained by the impossibility to distinguish between the active and the inactive form of the protease with the commercially available assays.
In many cases the findings are based on up- or downregulated expression of MMP genes, which do not necessarily translate into an increased presence of active proteases. This is the main limitation in the use of MMPs and TIMPs as markers of renal fibrosis. Given the functional complexity of the MMPs, it is likely that they themselves might not be suitable biomarkers of renal fibrosis.

\section{Protein fingerprint technology}

A highly regulated equilibrium between synthesis and degradation of ECM proteins is required to maintain tissue homeostasis. A disruption of this equilibrium is at the base of pathological processes such as fibrosis [104]. The measurement of the ECM remodelling rate, represented by end-products of ECM proteins in the biological fluids [116], can give an indication on the disease activity and progression. The peptides generated by specific protein degradation by MMPs or other proteases involved in a specific disease provide a unique fingerprint for a particular disease [117]. This approach is called protein fingerprint (Figure 2a). Compared to measurement of the intact/whole protein, the measurement of such modified 'fingerprint' peptides are likely to be more sensitive markers of pathology. This is because only the action of a specific protease (or other post-translational modifications) on a specific protein that is accumulated in a particular diseased tissue can generate the new $\mathrm{N}$ - or C-terminal, namely the neo-epitope.

The peptides originating from the protease-mediated degradation of the ECM may be small enough to be released in circulation or urine. There they can be detected

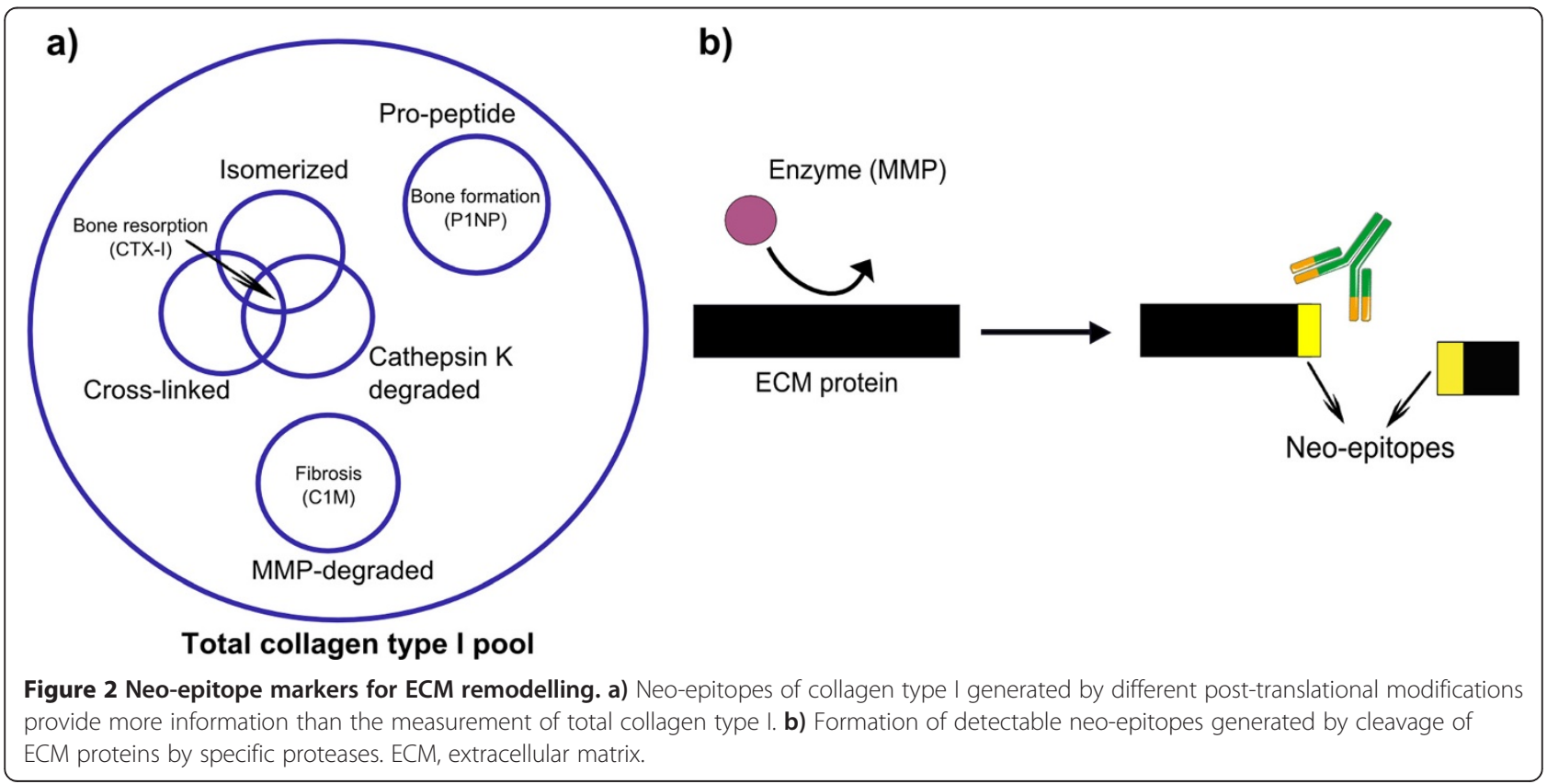


by antibodies raised specifically to react against the neo-epitope (Figure 2b). Other post-translational modifications, for example isomerization, citrullination, glycosylation and cross-linking can also originate from neo-epitopes to be used for protein fingerprint [118], but will be not discussed here. Markers reflecting ECM remodelling can not only identify and quantify a pathological process within the organ of interest, but can potentially describe the disease activity. This might for example help to segregate the patients that progress faster with the disease. Markers reflecting the disrupted ECM turnover might detect tissue modifications, which happen in the first stages of the disease when the pathological process can possibly still be reversed.

As outlined above, surprisingly very little data exists on the use of ECM, the principal underlying structure of fibrotic tissue, as a source of biomarkers of renal fibrosis. Such biomarkers could identify the early modifications that lead to renal fibrosis and could allow early treatment, helping in the resolution of fibrosis. Figure 3 illustrates the possible advantages of markers of structural changes over markers of loss of kidney function.

Neo-epitopes of different types of collagen (type I, II, III, IV, V and VI collagen), proteoglycans (biglycan and versican) and elastin have already proven to be biomarkers of connective tissue diseases, such as osteoarthritis [119] or organ fibrosis, in both animal models and clinical studies [120-130].

Experimental evidence in well-characterized animal models showed that neo-epitope fragments of collagen type I (C1M), III (C3M), IV (C4M) and V (C5M), biglycan (BGM) MMP-mediated degradation, and of collagen type III (Pro-C3), IV (P4NP 7S) and V (P5NP) formation were markers of liver fibrosis [120,126-129,131]. These markers (except BGM) also showed a promising potential for

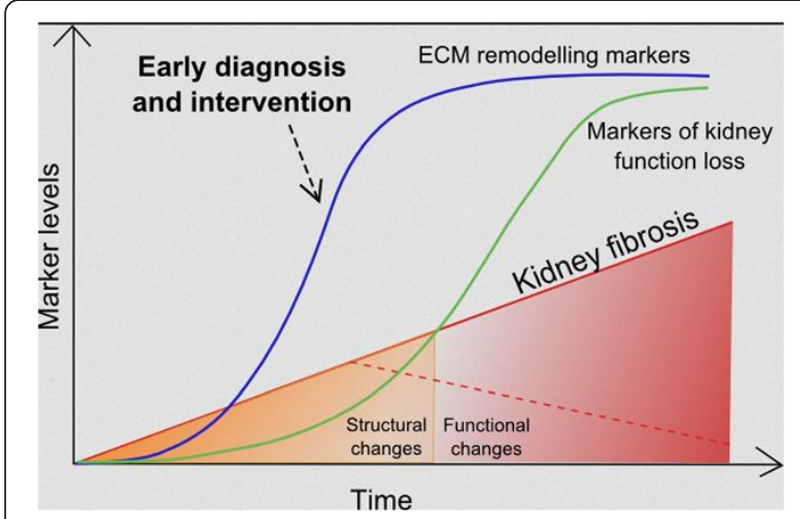

Figure 3 Biomarkers of ECM remodelling may identify molecular processes occurring in the early phases of fibrogenesis, giving the opportunity for early intervention in stages in which the disease is still reversible. The development of fibrosis is schematically indicated as linear for simplicity. ECM, extracellular matrix. monitoring the efficacy of the treatment with statins in an experimental model of liver fibrosis [132]. C3M was elevated in urine of mice treated with bleomycin to induce skin fibrosis compared to the controls, showing a potential use of this marker in skin fibrosis [125].

Clinical studies showed that the markers BGM, elastin MMP-generated neo-epitope fragment (ELM) C1M, C3M, C4M C5M, collagen type VI MMP-generated neo-epitope fragment $(\mathrm{C} 6 \mathrm{M})$, Pro-C3 and P4NP 7S were associated with portal hypertension in patients with cirrhosis, reflecting the degree of liver dysfunction [123]. A marker of MMP-mediated versican degradation (VCANM) was elevated in plasma of patients suffering from different cardiovascular diseases [130]. Promising clinical results were also obtained in lung fibrosis: the previously mentioned ELM [124] C1M, C3M, C4M, C5M and C6M [121] could separate patients affected by chronic obstructive pulmonary disease (COPD) and idiopathic pulmonary fibrosis (IPF) from healthy individuals in a small observational cohort.

As the mechanisms of kidney, liver and lung fibrosis share common features and involve similar ECM proteins, the successful biomarkers identified in these pre-clinical and clinical studies are also likely to prove valuable in renal fibrosis, as a first study in kidney patients suggests. Plasma levels of P4NP 7S were significantly associated with mortality in ESRD patients undergoing hemodialysis [122]. Specifically, the patients in the highest quartile of P4NP 7S plasma levels had an increased risk of death compared to the patients in the other quartiles. The high plasma levels of this marker were considered a sign of accelerated systemic fibrosis in ESRD patients with the worst prognosis. These results confirm the high value of collagen type IV as a prognostic marker in kidney diseases demonstrated by the previously described studies. The before mentioned results were obtained in urine and using an assay based on polyclonal antibodies, while in this study, an assay using a specific monoclonal antibody for the $\alpha 1$ chain of the P4NP 7S domain of collagen type IV was used to detect collagen type IV in plasma [133].

The main limitation of this technique in kidneys is that neo-epitope peptides coming from organs other than kidneys can also contribute to the pool of neo-epitopes detected in serum or plasma. Urine is a more suitable matrix to find protein fragments originating in the kidney. However, the detection of protein fragments in urine can be biased by the altered GFR during the late stages of CKD: lower or higher levels of the markers cannot be a result of lower or higher remodelling, but of impaired excretion. Furthermore, the urinary concentration of the markers can be altered by non-selective proteinuria in proteinuric kidney disease. The picture is further complicated by the frequent presence of comorbidities affecting other organs in the presence of 
kidney diseases, or even causing kidney diseases in the first place.

The challenge to identify a disease- and/or organ-specific and sensitive biomarker for renal fibrosis might be met by narrowing the selection of neo-epitopes to ECM protein or protein isoforms that are most exclusively expressed in kidneys and the action of a protease whose expression is up-regulated specifically during the pathogenesis of renal fibrosis.

\section{Conclusions}

The identification of reliable biomarkers for early diagnosis and prognosis of renal fibrosis is of paramount importance. The perfect biomarker for kidney fibrosis should be non-invasive, specific, involved in the mechanisms of fibrosis, with low (or no) background in healthy individuals and able to reflect treatment effects. Several molecules implicated in the mechanisms of fibrosis have been proposed as biomarkers, but none of them have been validated and accepted in clinical practice yet. In this review we have proposed a new perspective, introducing the possible use of ECM protein fingerprint as a source of novel biomarkers for renal fibrosis.

\section{Additional file}

Additional file 1: Table S1. Pre-clinical and clinical experimental evidence of involvement of extracellular matrix (ECM) protein and proteases in kidney disease [14,53,55-59,63,69-73,77-79,83-86,90,94,97, 99-101,112,113,115,134-154].

\section{Abbreviations}

ACR: Albumin to creatinine ratio; ADAM: A disintegrin and metalloproteinase; ADAMTS: A disintegrin and metalloproteinase with thrombospondin motifs; ADMA: Asymmetric dimethylarginine; ADPKD: Autosomal dominant polycystic kidney disease; ANCA: Anti-neutrophil cytoplasmic antibody; BGM: MMP-generated neo-epitope fragment of biglycan; BUN: Blood urea nitrogen; C1M: MMP-generated neo-epitope fragment of collagen type I; C3M: MMP-generated neo-epitope fragment of collagen type III; C4M: MMPgenerated neo-epitope fragment of collagen type IV; C5M: MMP-generated neo-epitope fragment of collagen type $\mathrm{V}$; C6M: MMP-generated neo-epitope fragment of collagen type Vl; CKD: Chronic kidney disease; COPD: Chronic obstructive pulmonary disease; CRP: C-reactive protein; DN: Diabetic nephropathy; ECM: Extracellular matrix; eGFR: Estimated glomerular filtration rate; ELM: MMP-generated neo-epitope fragment of elastin; ESRD: End-stage renal disease; FGF: Fibroblast growth factor; FGF-R1: Fibroblast growth factor receptor 1; GAG: Glycosaminoglycan; GBM: Glomerular basement membrane; GFR: Glomerular filtration rate; GGT: Gamma-glutamyl transpeptidase; IgAN: IgA nephropathy; IGF: Insulin-like growth factor; IPF: Idiopathic pulmonary fibrosis; KIM-1: Kidney injury molecule 1; L-FABP: Liver-type fatty acid-binding protein; MESA: Multi-Ethnic Study of Atherosclerosis; MeSH: Medical Subject Headings; MMP: Matrix metalloproteinase; MRE: Magnetic resonance elastography; NAG: N-acetyl-beta-Dglucosaminidase; NGAL: Neutrophil gelatinase-associated lipocalin; $\mathrm{NIH}$ : National Institutes of Health; P4NP 7S: Collagen type IV fragment belonging to the 7S domain; P5NP: Collagen type $V$ pro-peptide; PAI1: Plasminogen activator inhibitor-1; PDGF: Platelet-derived growth factor: PIIINP: Collagen type III N-terminal pro-peptide; Pro-C3: Propeptide of collagen type III; PSTC: Predictive Safety Testing Consortium; SLRP: Small leucine-rich proteoglycan; T4C: Collagen type IV to creatinine ratio; TGF- 31 : Transforming growth factor beta 1; TIMP: Tissue inhibitors of metalloproteinase; TNFR: Tumor necrosis factor receptor; uPIIINP/Cr: Urinary
PIIINP to creatinine ratio; UUO: Unilateral ureteral obstruction; VCANM: MMPmediated versican degradation fragment.

\section{Competing interests}

FG, MK and DL are full-time employees at Nordic Bioscience, Herlev, Denmark. Other authors have no competing interests.

\section{Authors' contributions}

FG, AM, MK and DL conceived and designed the review. FG, AM and PB carried out the literature research and drafted the manuscript. PB, DL and MK critically revised the manuscript for important intellectual content. All authors read and approved the final manuscript.

\section{Acknowledgements}

This work was supported by research grants TP25 and Q1 of the SFB/Transregio 57 of the German Research Foundation (Deutsche Forschungsgemeinschaft, DFG) 'Mechanisms of organ fibrosis', BO 3755/1-1 of the DFG and 2012_A216 of the Else-Kröner Fresenius Stiftung (EKFS), all to PB.

\section{Author details}

${ }^{1}$ Nordic Bioscience, 2730 Herlev, Denmark. ${ }^{2}$ Nephrology and Immunology, RWTH Aachen University, Aachen, North Rhine-Westphalia, Germany. ${ }^{3}$ Institute of Pathology, RWTH Aachen University, Aachen, North Rhine-Westphalia, Germany. ${ }^{4}$ Institute of Molecular Biomedicine, Comenius University, Bratislava, Slovakia.

Received: 21 November 2013 Accepted: 27 February 2014 Published: 28 March 2014

\section{References}

1. U.S. Renal Data System, USRDS 2013 Annual Data Report: Atlas of Chronic Kidney Disease and End-Stage Renal Disease in the United States, National Institutes of Health, National Institute of Diabetes and Digestive and Kidney Diseases. Bethesda, MD; 2013.

2. Barnes $\lrcorner$, Glass WF: Renal interstitial fibrosis: a critical evaluation of the origin of myofibroblasts. Contrib Nephrol 2011, 169:73-93.

3. Friedman SL, Sheppard D, Duffield JS, Violette S: Therapy for fibrotic diseases: nearing the starting line. Sci Trans/ Med 2013, 5:167sr1.

4. Boor P, Sebekova K, Ostendorf T, Floege J: Treatment targets in renal fibrosis. Nephrol Dial Transplant 2007, 22:3391-3407.

5. Eddy AA: Molecular basis of renal fibrosis. Pediatr Nephrol 2000, 15:290-301.

6. Boor P, Ostendorf T, Floege J: Renal fibrosis: novel insights into mechanisms and therapeutic targets. Nat Rev Nephrol 2010, 6:643-656.

7. Liu Y: Cellular and molecular mechanisms of renal fibrosis. Nat Rev Nephrol 2011, 7:684-696.

8. Boor P, Konieczny A, Villa L, Kunter U, Van Roeyen CR, LaRochelle WJ, Smithson G, Arrol S, Ostendorf T, Floege J: PDGF-D inhibition by CR002 ameliorates tubulointerstitial fibrosis following experimental glomerulonephritis. Nephrol Dial Transplant 2007, 22:1323-1331.

9. Boor P, Floege J: Chronic kidney disease growth factors in renal fibrosis. Clin Exp Pharmacol Physiol 2011, 38:441-450.

10. Fogo AB: Renal fibrosis: not just PAl-1 in the sky. J Clin Invest 2003, 112:326-328.

11. Malgorzewicz S, Skrzypczak-Jankun E, Jankun J: Plasminogen activator inhibitor-1 in kidney pathology (Review). Int J Mol Med 2013, 31:503-510.

12. Boor P, Floege J: The renal (myo-)fibroblast: a heterogeneous group of cells. Nephrol Dial Transplant 2012, 27:3027-3036.

13. Lebleu VS, Taduri G, O'Connell J, Teng Y, Cooke VG, Woda C, Sugimoto H, Kalluri R: Origin and function of myofibroblasts in kidney fibrosis. Nat Med 2013, 19:1047-1053.

14. Eddy AA: Molecular insights into renal interstitial fibrosis. J Am Soc Nephrol 1996, 7:2495-2508.

15. Farris $A B$, Colvin RB: Renal interstitial fibrosis: mechanisms and evaluation. Curr Opin Nephrol Hypertens 2012, 21:289-300.

16. Goldsmith D, Jayawardene S, Ackland P: ABC of Kidney Disease. 2nd edition. Chichester: John Wiley \& Sons, Ltd; 2013.

17. Kirk GD, Astemborski J, Mehta SH, Spoler C, Fisher C, Allen D, Higgins Y, Moore RD, Afdhal N, Torbenson M, Sulkowski M, Thomas DL: Assessment of liver fibrosis by transient elastography in persons with hepatitis $C$ virus 
infection or HIV-hepatitis C virus coinfection. Clin Infect Dis 2009, 48:963-972.

18. Korsmo MJ, Ebrahimi B, Eirin A, Woollard JR, Krier JD, Crane JA, Warner L, Glaser K, Grimm R, Ehman RL, Lerman LO: Magnetic resonance elastography noninvasively detects in vivo renal medullary fibrosis secondary to swine renal artery stenosis. Invest Radiol 2013, 48:61-68.

19. Fassett RG, Venuthurupalli SK, Gobe GC, Coombes JS, Cooper MA, Hoy WE: Biomarkers in chronic kidney disease: a review. Kidney Int 2011, 80:806-821.

20. O'Callaghan C: The Renal System at a Glance. 3rd edition. Chichester: John Wiley \& Sons, Ltd; 2009.

21. Waikar SS, Bonventre JV: Can we rely on blood urea nitrogen as a biomarker to determine when to initiate dialysis? Clin J Am Soc Nephrol 2006, 1:903-904.

22. D'Amico G, Bazzi C: Pathophysiology of proteinuria. Kidney Int 2003, 63:809-825.

23. Newman DJ, Thakkar H, Edwards RG, Wilkie M, White T, Grubb AO, Price CP: Serum cystatin $C$ measured by automated immunoassay: a more sensitive marker of changes in GFR than serum creatinine. Kidney Int 1995, 47:312-318.

24. Hoffmann A, Nimtz M, Conradt HS: Molecular characterization of beta-trace protein in human serum and urine: a potential diagnostic marker for renal diseases. Glycobiology 1997, 7:499-506.

25. Bonventre JV, Vaidya VS, Schmouder R, Feig P, Dieterle F: Next-generation biomarkers for detecting kidney toxicity. Nat Biotechnol 2010, 28:436-440.

26. Ravani P, Tripepi G, Malberti F, Testa S, Mallamaci F, Zoccali C: Asymmetrical dimethylarginine predicts progression to dialysis and death in patients with chronic kidney disease: a competing risks modeling approach. J Am Soc Nephrol 2005, 16:2449-2455.

27. Chen J, Hamm LL, Kleinpeter MA, Husserl F, Khan IE, Chen CS, Liu Y, Mills $K T$, He C, Rifai N, Simon EE, He J: Elevated plasma levels of endostatin are associated with chronic kidney disease. Am J Nephrol 2012, 35:335-340.

28. Jonsson KB: The role of fibroblast growth factor 23 in renal disease. Nephrol Dial Transplant 2005, 20:479-482.

29. Gutiérrez OM, Mannstadt M, Isakova T, Rauh-Hain JA, Tamez H, Shah A, Smith $K$, Lee $H$, Thadhani $R$, Jüppner $H$, Wolf M: Fibroblast growth factor 23 and mortality among patients undergoing hemodialysis. N Engl J Med 2008, 359:584-592.

30. Kendrick J, Cheung AK, Kaufman JS, Greene T, Roberts WL, Smits G, Chonchol M: FGF-23 associates with death, cardiovascular events, and initiation of chronic dialysis. J Am Soc Nephrol 2011, 12:1913-1922.

31. Isakova $T$, Xie H, Yang W, Xie D, Anderson AH, Scialla J, Wahl P, Gutierrez OM, Steigerwalt S, He J, Schwartz S, Lo J, Ojo A, Sondheimer J, Hsu CY, Lash J, Leonard M, Kusek JW, Feldman HI, Wolf M, Chronic Renal Insufficiency Cohort (CRIC) Study Group: Fibroblast growth factor 23 and risks of mortality and end-stage renal disease in patients with chronic kidney disease. JAMA 2011, 305:2432-2439.

32. Wolf M: Update on fibroblast growth factor 23 in chronic kidney disease. Kidney Int 2012, 82:737-747.

33. Wang G, Lai FM, Lai KB, Chow KM, Li KT, Szeto CC: Messenger RNA expression of podocyte-associated molecules in the urinary sediment of patients with diabetic nephropathy. Nephron Clin Pract 2007, 106:c169-c179.

34. Kanno K, Kawachi H, Uchida Y, Hara M, Shimizu F, Uchiyama M: Urinary sediment podocalyxin in children with glomerular diseases. Nephron Clin Pract 2003, 95:c91-c99.

35. Bolignano D, Lacquaniti A, Coppolino G, Donato V, Campo S, Fazio MR, Nicocia G, Buemi M: Neutrophil gelatinase-associated lipocalin (NGAL) and progression of chronic kidney disease. Clin J Am Soc Nephrol 2009, 4:337-344.

36. Lim Al, Tang SC, Lai KN, Leung JC: Kidney injury molecule-1: more than just an injury marker of tubular epithelial cells? J Cell Physiol 2013, 228:917-924.

37. van Timmeren MM, van den Heuvel MC, Bailly V, Bakker SJ, van Goor H, Stegeman CA: Tubular kidney injury molecule-1 (KIM-1) in human renal disease. J Pathol 2007, 212:209-217

38. Kern EF, Erhard P, Sun W, Genuth S, Weiss MF: Early urinary markers of diabetic kidney disease: a nested case-control study from the Diabetes Control and Complications Trial (DCCT). Am J Kidney Dis 2010, 55:824-834.

39. Holdt-Lehmann B, Lehmann A, Korten G, Nagel H, Nizze H, Schuff-Werner P: Diagnostic value of urinary alanine aminopeptidase and $\mathrm{N}$-acetyl-beta-D- glucosaminidase in comparison to alpha 1-microglobulin as a marker in evaluating tubular dysfunction in glomerulonephritis patients. Clin Chim Acta 2000, 297:93-102.

40. Kamijo A, Kimura K, Sugaya T, Yamanouchi M, Hikawa A, Hirano N, Hirata Y, Goto A, Omata M: Urinary fatty acid-binding protein as a new clinical marker of the progression of chronic renal disease. J Lab Clin Med 2004, 143:23-30.

41. Nielsen SE, Sugaya T, Hovind P, Baba T, Parving HH, Rossing P: Urinary liver-type fatty acid-binding protein predicts progression to nephropathy in type 1 diabetic patients. Diabetes Care 2010, 33:1320-1324.

42. Malyszko J, Malyszko JS, Bachorzewska-Gajewska H, Poniatowski B, Dobrzycki S, Mysliwiec M: Neutrophil gelatinase-associated lipocalin is a new and sensitive marker of kidney function in chronic kidney disease patients and renal allograft recipients. Transplant Proc 2009, 41:158-161.

43. Shlipak MG, Day EC: Biomarkers for incident CKD: a new framework for interpreting the literature. Nat Rev Nephrol 2013, 9:478-483.

44. Peralta CA, Katz R, Bonventre JV, Sabbisetti V, Siscovick D, Sarnak M, Shlipak MG: Associations of urinary levels of kidney injury molecule 1 (KIM-1) and neutrophil gelatinase-associated lipocalin (NGAL) with kidney function decline in the Multi-Ethnic Study of Atherosclerosis (MESA). Am J Kidney Dis 2012, 60:904-911.

45. Roth GA, Lebherz-Eichinger D, Ankersmit HJ, Hacker S, Hetz H, Vukovich T, Perne A, Reiter T, Farr A, Hörl WH, Haas M, Krenn CG: Increased total cytokeratin-18 serum and urine levels in chronic kidney disease. Clin Chim Acta 2011, 412:713-717.

46. Bosman FT, Stamenkovic I: Functional structure and composition of the extracellular matrix. J Pathol 2003, 200:423-428.

47. Chen YM, Miner JH: Glomerular basement membrane and related glomerular disease. Transl Res 2012, 160:291-297.

48. Shannon MB, Patton BL, Harvey SJ, Miner JH: A hypomorphic mutation in the mouse laminin alpha5 gene causes polycystic kidney disease. J Am Soc Nephrol 2006, 17:1913-1922.

49. Abrass CK, Hansen KM, Patton BL: Laminin alpha4-null mutant mice develop chronic kidney disease with persistent overexpression of platelet-derived growth factor. Am J Pathol 2010, 176:839-849.

50. Fischer $E$, Mougenot B, Callard P, Ronco P, Rossert J: Abnormal expression of glomerular basement membrane laminins in membranous glomerulonephritis. Nephrol Dial Transplant 2000, 15:1956-1964.

51. Rheault MN, Kren SM, Thielen BK, Mesa HA, Crosson JT, Thomas W, Sado Y, Kashtan CE, Segal Y: Mouse model of X-linked Alport syndrome. J Am SoC Nephrol 2004, 15:1466-1474.

52. Hudson BG, Tryggvason K, Sundaramoorthy M, Neilson EG: Alport's syndrome, Goodpasture's syndrome, and type IV collagen. N Engl J Med 2003, 348:2543-2556.

53. Kawase T, Shimizu A, Adachi E, Tojimbara T, Nakajima I, Fuchinoue S, Sawada T: Collagen IV is upregulated in chronic transplant nephropathy. Transplant Proc 2001, 33:1207-1208.

54. Boor P, Celec P, Behuliak M, Grancic P, Kebis A, Kukan M, Pronayova N, Liptaj T, Ostendorf T, Sebekova K: Regular moderate exercise reduces advanced glycation and ameliorates early diabetic nephropathy in obese Zucker rats. Metabolism 2009, 58:1669-1677.

55. Morita M, Uchigata Y, Hanai K, Ogawa Y, Iwamoto Y: Association of urinary type IV collagen with GFR decline in young patients with type 1 diabetes. Am J Kidney Dis 2011, 58:915-920.

56. Okonogi $H$, Nishimura M, Utsunomiya $Y$, Hamaguchi $K$, Tsuchida $H$, Miura $Y$, Suzuki S, Kawamura T, Hosoya T, Yamada K: Urinary type IV collagen excretion reflects renal morphological alterations and type IV collagen expression in patients with type 2 diabetes mellitus. Clin Nephrol 2001, 55:357-364.

57. Araki S, Haneda M, Koya D, Isshiki K, Kume S, Sugimoto T, Kawai H, Nishio Y, Kashiwagi A, Uzu T, Maegawa H: Association between urinary type IV collagen level and deterioration of renal function in type 2 diabetic patients without overt proteinuria. Diabetes Care 2010, 33:1805-1810.

58. Furumatsu Y, Nagasawa Y, Shoji T, Yamamoto R, lio K, Matsui I, Takabatake Y, Kaimori JY, Iwatani H, Kaneko T, Tsubakihara Y, Imai E, Isaka Y, Rakugi H: Urinary type IV collagen in nondiabetic kidney disease. Nephron Clin Pract 2011, 117:C160-c166

59. Merchant ML, Perkins BA, Boratyn GM, Ficociello LH, Wilkey DW, Barati MT, Bertram CC, Page GP, Rovin BH, Warram JH, Krolewski AS, Klein JB: Urinary peptidome may predict renal function decline in type 1 diabetes and microalbuminuria. J Am Soc Nephrol 2009, 20:2065-2074. 
60. Hurskainen T, Moilanen J, Sormunen R, Franzke CW, Soininen R, Loeffek S, Huilaja L, Nuutinen M, Bruckner-Tuderman L, Autio-Harmainen H, Tasanen K: Transmembrane collagen XVII is a novel component of the glomerular filtration barrier. Cell Tissue Res 2012, 348:579-588.

61. Miner JH: The glomerular basement membrane. Exp Cell Res 2012, 318:973-978.

62. Schaefer L, Schaefer RM: Proteoglycans: from structural compounds to signaling molecules. Cell Tissue Res 2010, 339:237-246.

63. Ebefors K, Granqvist A, Ingelsten M, Molne J, Haraldsson B, Nystrom J: Role of glomerular proteoglycans in IgA nephropathy. PLOS One 2011, 6:e18575.

64. Goldberg S, Harvey SJ, Cunningham J, Tryggvason K, Miner JH: Glomerular filtration is normal in the absence of both agrin and perlecan-heparan sulfate from the glomerular basement membrane. Nephrol Dial Transplant 2009, 24:2044-2051.

65. van den Hoven MJ, Wijnhoven TJ, Li JP, Zcharia E, Dijkman HB, Wismans RG, Rops $A L$, Lensen JF, van den Heuvel LP, van Kuppevelt TH, Vlodavsky I, Berden $\mathrm{JH}$, van der Vlag J: Reduction of anionic sites in the glomerular basement membrane by heparanase does not lead to proteinuria. Kidney Int 2008, 73:278-287.

66. Harvey SJ, Jarad G, Cunningham J, Rops AL, van der Vlag J, Berden JH, Moeller MJ, Holzman LB, Burgess RW, Miner JH: Disruption of glomerular basement membrane charge through podocyte-specific mutation of agrin does not alter glomerular permselectivity. Am J Pathol 2007, 171:139-152.

67. Schlondorff $D$, Banas $B$ : The mesangial cell revisited: no cell is an island. J Am Soc Nephrol 2009, 20:1179-1187.

68. Barratt J, Smith AC, Molyneux K, Feehally J: Immunopathogenesis of IgAN Semin Immunopathol 2007, 29:427-443.

69. Mason RM, Wahab NA: Extracellular matrix metabolism in diabetic nephropathy. J Am Soc Nephrol 2003, 14:1358-1373.

70. Schaefer L, Grone HJ, Raslik I, Robenek H, Ugorcakova J, Budny S, Schaefer RM, Kresse H: Small proteoglycans of normal adult human kidney: distinct expression patterns of decorin, biglycan, fibromodulin, and lumican. Kidney Int 2000, 58:1557-1568.

71. Cohen MP, Lautenslager GT, Shearman CW: Increased urinary type IV collagen marks the development of glomerular pathology in diabetic d/db mice. Metabolism 2001, 50:1435-1440.

72. lo H, Hamada C, Fukui M, Horikoshi S, Tomino Y: Relationship between levels of urinary type IV collagen and renal injuries in patients with IgA nephropathy. J Clin Lab Anal 2004, 18:14-18.

73. Johnson TS, Haylor JL, Thomas GL, Fisher M, El Nahas AM: Matrix metalloproteinases and their inhibitions in experimental renal scarring. Exp Nephrol 2002, 10:182-195.

74. Hornigold N, Johnson TS, Huang L, Haylor JL, Griffin M, Mooney A Inhibition of collagen I accumulation reduces glomerulosclerosis by a Hic-5-dependent mechanism in experimental diabetic nephropathy. Lab Invest 2013, 93:553-565.

75. Keeling J, Herrera GA: Human matrix metalloproteinases: characteristics and pathologic role in altering mesangial homeostasis. Microsc Res Tech 2008, 71:371-379.

76. Rozario T, DeSimone DW: The extracellular matrix in development and morphogenesis: a dynamic view. Dev Biol 2010, 341:126-140.

77. Sharma AK, Mauer SM, Kim Y, Michael AF: Interstitial fibrosis in obstructive nephropathy. Kidney Int 1993, 44:774-788.

78. Bakun M, Niemczyk M, Domanski D, Jazwiec R, Perzanowska A, Niemczyk S, Kistowski M, Fabijanska A, Borowiec A, Paczek L, Dadlez M: Urine proteome of autosomal dominant polycystic kidney disease patients. Clin Proteomics 2012, 9:13.

79. Stokes MB, Holler S, Cui Y, Hudkins KL, Eitner F, Fogo A, Alpers CE: Expression of decorin, biglycan, and collagen type I in human renal fibrosing disease. Kidney Int 2000, 57:487-498

80. Rossing K, Mischak H, Dakna M, Zurbig P, Novak J, Julian BA, Good DM, Coon JJ, Tarnow L, Rossing P: Urinary proteomics in diabetes and CKD. J Am Soc Nephrol 2008, 19:1283-1290.

81. Soylemezoglu O, Wild G, Dalley AJ, MacNeil S, Milford-Ward A, Brown CB, el Nahas AM: Urinary and serum type III collagen: markers of renal fibrosis. Nephrol Dial Transplant 1997, 12:1883-1889.

82. Teppo AM, Tornroth T, Honkanen E, Gronhagen-Riska C: Urinary aminoterminal propeptide of type III procollagen (PIIINP) as a marker of interstitial fibrosis in renal transplant recipients. Transplantation 2003, 75:2113-2119.
83. Ghoul BE, Squalli T, Servais A, Elie C, Meas-Yedid V, Trivint C, Vanmassenhove J, Grunfeld JP, Olivo-Marin JC, Thervet E, Noël LH, Prié D, Fakhouri F: Urinary procollagen III aminoterminal propeptide (PIIINP): a fibrotest for the nephrologist. Clin J Am Soc Nephrol 2010, 5:205-210.

84. Vleming LJ, Baelde JJ, Westendorp RG, Daha MR, van Es LA, Bruijn JA: Progression of chronic renal disease in humans is associated with the deposition of basement membrane components and decorin in the interstitial extracellular matrix. Clin Nephrol 1995, 44:211-219.

85. Okuda S, Languino LR, Ruoslahti E, Border WA: Elevated expression of transforming growth factor-beta and proteoglycan production in experimental glomerulonephritis. Possible role in expansion of the mesangial extracellular matrix. J Clin Invest 1990, 86:453-462.

86. Hugo C, Shankland SJ, Pichler RH, Couser WG, Johnson RJ: Thrombospondin 1 precedes and predicts the development of tubulointerstitial fibrosis in glomerular disease in the rat. Kidney Int 1998, 53:302-311.

87. Frantz C, Stewart KM, Weaver VM: The extracellular matrix at a glance. J Cell Sci 2010, 123:4195-4200.

88. Border WA, Noble NA, Yamamoto T, Harper JR, Yamaguchi Y, Pierschbacher $M D$, Ruoslahti E: Natural inhibitor of transforming growth factor-beta protects against scarring in experimental kidney disease. Nature 1992, 360:361-364.

89. Schaefer L: Extracellular matrix molecules: endogenous danger signals as new drug targets in kidney diseases. Curr Opin Pharmacol 2010, 10:185-190.

90. Diamond JR, Levinson M, Kreisberg R, Ricardo SD: Increased expression of decorin in experimental hydronephrosis. Kidney Int 1997, 51:1133-1139.

91. Lebleu VS, Teng Y, O'Connell JT, Charytan D, Muller GA, Muller CA, Sugimoto $H$, Kalluri R: Identification of human epididymis protein-4 as a fibroblast-derived mediator of fibrosis. Nat Med 2013, 19:227-231.

92. Schaefer L: Small leucine-rich proteoglycans in kidney disease. J Am SoC Nephrol 2011, 22:1200-1207.

93. Isaka Y, Brees DK, Ikegaya K, Kaneda Y, Imai E, Noble NA, Border WA: Gene therapy by skeletal muscle expression of decorin prevents fibrotic disease in rat kidney. Nat Med 1996, 2:418-423.

94. Stridh S, Palm F, Hansell P: Renal interstitial hyaluronan: functional aspects during normal and pathological conditions. Am J Physiol Regul Integr Comp Physiol 2012, 302:R1235-R1249.

95. Wight TN: Versican: a versatile extracellular matrix proteoglycan in cell biology. Curr Opin Cell Biol 2002, 14:617-623.

96. Bode-Lesniewska B, Dours-Zimmermann MT, Odermatt BF, Briner J, Heitz PU, Zimmermann DR: Distribution of the large aggregating proteoglycan versican in adult human tissues. J Histochem Cytochem 1996, 44:303-312.

97. Rudnicki M, Perco P, Neuwirt H, Noppert SJ, Leierer J, Sunzenauer J, Eder S, Zoja C, Eller K, Rosenkranz AR, Müller GA, Mayer B, Mayer G: Increased renal versican expression is associated with progression of chronic kidney disease. PLoS One 2012, 7:e44891.

98. Shiomi T, Lemaitre $V$, D'Armiento J, Okada Y: Matrix metalloproteinases, a disintegrin and metalloproteinases, and a disintegrin and metalloproteinases with thrombospondin motifs in non-neoplastic diseases. Pathol Int 2010, 60:477-496.

99. Mulder GM, Melenhorst WB, Celie JW, Kloosterhuis NJ, Hillebrands JL, Ploeg $R J$, Seelen MA, Visser L, van Dijk MC, van Goor H: ADAM17 up-regulation in renal transplant dysfunction and non-transplant-related renal fibrosis. Nephrol Dial Transplant 2012, 27:2114-2122.

100. Melenhorst WB, van den Heuvel MC, Timmer A, Huitema S, Bulthuis M, Timens W, van Goor H: ADAM19 expression in human nephrogenesis and renal disease: associations with clinical and structural deterioration. Kidney Int 2006, 70:1269-1278.

101. Melenhorst WB, van den Heuvel MC, Stegeman CA, van der L, Huitema S, van den BA, van Goor H: Upregulation of ADAM19 in chronic allograft nephropathy. Am J Transplant 2006, 6:1673-1681.

102. Nakamura A, Sakai Y, Ohata C, Komurasaki T: Expression and significance of a disintegrin and metalloproteinase with thrombospondin motifs (ADAMTS)-1 in an animal model of renal interstitial fibrosis induced by unilateral ureteral obstruction. Exp Toxicol Pathol 2007, 59:1-7.

103. Jamale TE, Hase NK, Kulkarni M, Iqbal AM, Rurali E, Kulkarni MG, Shetty P, Pradeep KJ: Hereditary ADAMTS 13 deficiency presenting as recurrent acute kidney injury. Indian J Nephrol 2012, 22:298-300.

104. Lu P, Takai K, Weaver VM, Werb Z: Extracellular matrix degradation and remodeling in development and disease. Cold Spring Harb Perspect Biol 2011, 3:pii:a005058. 
105. Nagase $H$, Visse R, Murphy $G$ : Structure and function of matrix metalloproteinases and TIMPs. Cardiovasc Res 2006, 69:562-573.

106. Altemtam N, Nahas ME, Johnson T: Urinary matrix metalloproteinase activity in diabetic kidney disease: a potential marker of disease progression. Nephron Extra 2012, 2:219-232

107. Rao VH, Meehan DT, Delimont D, Nakajima M, Wada T, Gratton MA, Cosgrove D: Role for macrophage metalloelastase in glomerular basement membrane damage associated with alport syndrome. Am J Pathol 2006, 169:32-46.

108. Tan RJ, Liu Y: Matrix metalloproteinases in kidney homeostasis and diseases. Am J Physiol Renal Physiol 2012, 302:F1351-F1361.

109. Catania JM, Chen G, Parrish AR: Role of matrix metalloproteinases in renal pathophysiologies. Am J Physiol Renal Physiol 2007, 292:F905-F911.

110. Pardo A, Selman M: Matrix metalloproteases in aberrant fibrotic tissue remodeling. Proc Am Thorac Soc 2006, 3:383-388.

111. Turck J, Pollock AS, Lee LK, Marti HP, Lovett DH: Matrix metalloproteinase 2 (gelatinase A) regulates glomerular mesangial cell proliferation and differentiation. J Biol Chem 1996, 271:15074-15083.

112. Gonzalez-Avila G, Iturria C, Vadillo-Ortega F, Ovalle C, Montano M: Changes in matrix metalloproteinases during the evolution of interstitial renal fibrosis in a rat experimental model. Pathobiology 1998, 66:196-204.

113. Schaefer L, Han X, Gretz N, Hafner C, Meier K, Matzkies F, Schaefer RM: Tubular gelatinase A (MMP-2) and its tissue inhibitors in polycystic kidney disease in the Han:SPRD rat. Kidney Int 1996, 49:75-81.

114. Tashiro K, Koyanagi I, Ohara I, Ito T, Saitoh A, Horikoshi S, Tomino Y: Levels of urinary matrix metalloproteinase-9 (MMP-9) and renal injuries in patients with type 2 diabetic nephropathy. J Clin Lab Anal 2004, 18:206-210.

115. Surendran K, Simon TC, Liapis H, McGuire JK: Matrilysin (MMP-7) expression in renal tubular damage: association with Wnt4. Kidney Int 2004, 65:2212-2222.

116. Karsdal MA, Bay-Jensen AC, Leeming DJ, Henriksen K, Christiansen C: Quantification of "end products" of tissue destruction in inflammation may reflect convergence of cytokine and signaling pathways - implications for modern clinical chemistry. Biomarkers 2013, 18:375-378.

117. Karsdal MA, Delvin E, Christiansen C: Protein fingerprints - relying on and understanding the information of serological protein measurements. Clin Biochem 2011, 44:1278-1279.

118. Karsdal MA, Nielsen MJ, Sand JM, Henriksen K, Genovese F, Bay-Jensen AC, Smith V, Adamkewicz Jl, Christiansen C, Leeming DJ: Extracellular matrix remodeling: the common denominator in connective tissue diseases. Possibilities for evaluation and current understanding of the matrix as more than a passive architecture, but a key player in tissue failure. Assay Drug Dev Technol 2013, 11:70-92.

119. Bay-Jensen AC, Liu Q, Byrjalsen I, Li Y, Wang J, Pedersen C, Leeming DJ, Dam EB, Zheng Q, Qvist P, Karsdal MA: Enzyme-linked immunosorbent assay (ELISAs) for metalloproteinase derived type II collagen neoepitope, CIIM-increased serum CIIM in subjects with severe radiographic osteoarthritis. Clin Biochem 2011, 44:423-429.

120. Leeming DJ, Byrjalsen I, Jimenez W, Christiansen C, Karsdal MA: Protein fingerprinting of the extracellular matrix remodelling in a rat model of liver fibrosis-a serological evaluation. Liver Int 2013, 33:439-447.

121. Leeming DJ, Sand JM, Nielsen MJ, Genovese F, Martinez FJ, Hogaboam CM, Han MK, Klickstein LB, Karsdal MA: Serological investigation of the collagen degradation profile of patients with chronic obstructive pulmonary disease or idiopathic pulmonary fibrosis. Biomark Insights 2012, 7:119-126

122. Leeming DJ, Karsdal MA, Rasmussen LM, Scholze A, Tepel M: Association of systemic collagen type IV formation with survival among patients undergoing hemodialysis. PLoS One 2013, 8:e71050

123. Leeming DJ, Karsdal MA, Byrjalsen I, Trebicka J, Nielsen MJ, Christiansen C, Møller S, Krag A: Novel serological neo-epitope markers of extracellular matrix proteins for the detection of portal hypertension. Aliment Pharmacol Ther 2013, 38:1086-1096.

124. Skjøt-Arkil $H$, Clausen RE, Nguyen QH, Wang Y, Zheng Q, Martinez FJ, Hogaboam CM, Han M, Klickstein LB, Larsen MR, Nawrocki A, Leeming DJ, Karsdal MA: Measurement of MMP-9 and -12 degraded elastin (ELM) provides unique information on lung tissue degradation. BMC Pulm Med 2012, 12:34.

125. Vassiliadis E, Veidal SS, Barascuk N, Mullick JB, Clausen RE, Larsen L, Simonsen H, Larsen DV, Bay-Jensen AC, Segovia-Silvestre T, Leeming DJ, Karsdal MA: Measurement of matrix metalloproteinase 9-mediated collagen type III degradation fragment as a marker of skin fibrosis. BMC Dermatol 2011, 11:6

126. Vassiliadis E, Larsen DV, Clausen RE, Veidal SS, Barascuk N, Larsen L, Simonsen H, Silvestre TS, Hansen C, Overgaard T, Leeming DJ, Karsdal MA: Measurement of CO3-610, a potential liver biomarker derived from matrix metalloproteinase-9 degradation of collagen type iii, in a rat model of reversible carbon-tetrachloride-induced fibrosis. Biomark Insights 2011, 6:49-58

127. Veidal SS, Karsdal MA, Vassiliadis E, Nawrocki A, Larsen MR, Nguyen QH, Hagglund $P$, Luo $Y$, Zheng Q, Vainer B, Leeming DJ: MMP mediated degradation of type $\mathrm{VI}$ collagen is highly associated with liver fibrosisidentification and validation of a novel biochemical marker assay. PLoS One 2011, 6:e24753.

128. Veidal SS, Karsdal MA, Nawrocki A, Larsen MR, Dai Y, Zheng Q, Hagglund P, Vainer B, Skjot-Arkil H, Leeming DJ: Assessment of proteolytic degradation of the basement membrane: a fragment of type IV collagen as a biochemical marker for liver fibrosis. Fibrogenesis Tissue Repair 2011, 4:22

129. Genovese F, Barascuk N, Larsen L, Larsen MR, Nawrocki A, Li Y, Zheng Q, Wang J, Veidal SS, Leeming DJ, Karsdal MA: Biglycan fragmentation in pathologies associated with extracellular matrix remodeling by matrix metalloproteinases. Fibrogenesis Tissue Repair 2013, 6:9.

130. Barascuk N, Genovese F, Larsen L, Byrjalsen I, Zheng Q, Sun S, Hosbond S, Poulsen TS, Diederichsen A, Jensen JM, Mickley H, Register TC, Rasmussen LM, Leeming DJ, Christiansen C, Karsdal MA: A MMP derived versican neo-epitope is elevated in plasma from patients with atherosclerotic heart disease. Int J Clin Exp Med 2013, 6:174-184.

131. Veidal SS, Vassiliadis E, Barascuk N, Zhang C, Segovia-Silvestre T, Klickstein L, Larsen MR, Qvist P, Christiansen C, Vainer B, Karsdal MA: Matrix metalloproteinase-9-mediated type III collagen degradation as a novel serological biochemical marker for liver fibrogenesis. Liver Int 2010, 30:1293-1304

132. Schierwagen R, Leeming DJ, Klein S, Granzow M, Nielsen MJ, Sauerbruch T, Krag A, Karsdal MA, Trebicka J: Serum markers of the extracellular matrix remodeling reflect antifibrotic therapy in bile-duct ligated rats. Front Physiol 2013, 4:195

133. Leeming DJ, Nielsen MJ, Dai Y, Veidal SS, Vassiliadis E, Zhang C, He Y, Vainer B, Zheng Q, Karsdal MA: Enzyme-linked immunosorbent serum assay specific for the 7S domain of Collagen Type IV (P4NP 7S): A marker related to the extracellular matrix remodeling during liver fibrogenesis. Hepatol Res 2012, 42:482-493.

134. limura O, Takahashi H, Yashiro T, Madoiwa S, Sakata Y, Asano Y, Kusano E: Effect of ureteral obstruction on matrix metalloproteinase- 2 in rat renal cortex. Clin Exp Nephrol 2004, 8:223-229.

135. Sharma AK, Mauer SM, Kim Y, Michael AF: Altered expression of matrix metalloproteinase-2, TIMP, and TIMP-2 in obstructive nephropathy. J Lab Clin Med 1995, 125:754-761.

136. Jain S, Bicknell GR, Nicholson ML: Molecular changes in extracellular matrix turnover after renal ischaemia-reperfusion injury. Br J Surg 2000, 87:1188-1192.

137. Camp TM, Smiley LM, Hayden MR, Tyagi SC: Mechanism of matrix accumulation and glomerulosclerosis in spontaneously hypertensive rats. J Hypertens 2003, 21:1719-1727.

138. Cheng S, Pollock AS, Mahimkar R, Olson JL, Lovett DH: Matrix metalloproteinase 2 and basement membrane integrity: a unifying mechanism for progressive renal injury. FASEB J 2006, 20:1898-1900

139. Inkinen KA, Soots AP, Krogerus LA, Lautenschlager IT, Ahonen JP: Fibrosis and matrix metalloproteinases in rat renal allografts. Transpl Int 2005, 18:506-512.

140. Wu K, Setty S, Mauer SM, Killen P, Nagase H, Michael AF, Tsilibary EC: Altered kidney matrix gene expression in early stages of experimental diabetes. Acta Anat (Basel) 1997, 158:155-165.

141. Portik-Dobos V, Harris AK, Song W, Hutchinson J, Johnson MH, Imig JD, Pollock DM, Ergul A: Endothelin antagonism prevents early EGFR transactivation but not increased matrix metalloproteinase activity in diabetes. Am J Physiol Regul Integr Comp Physiol 2006, 290:R435-R441.

142. Basile DP, Martin DR, Hammerman MR: Extracellular matrix-related genes in kidney after ischemic injury: potential role for TGF-beta in repair. Am J Physiol 1998, 275:F894-F903

143. Eddy AA: Expression of genes that promote renal interstitial fibrosis in rats with proteinuria. Kidney Int Supp/ 1996, 54:S49-S54.

144. Eddy AA: Interstitial inflammation and fibrosis in rats with diet-induced hypercholesterolemia. Kidney Int 1996, 50:1139-1149. 
145. Engelmyer $\mathrm{E}$, van $\mathrm{GH}$, Edwards DR, Diamond JR: Differential mRNA expression of renal cortical tissue inhibitor of metalloproteinase-1, -2 and -3 in experimental hydronephrosis. J Am Soc Nephrol 1995, 5:1675-1683.

146. Boor P, Celec P, Martin IV, Villa L, Hodosy J, Klenovicsová K, Esposito C, Schäfer S, Albrecht-Küpper B, Ostendorf T, Heidland A, Šebeková K: The peroxisome proliferator-activated receptor-alpha agonist, BAY PP1, attenuates renal fibrosis in rats. Kidney Int 2011, 80:1182-1197.

147. Boor P, Konieczny A, Villa L, Schult AL, Bucher E, Rong S, Kunter U, van Roeyen CR, Polakowski T, Hawlisch H, Hillebrandt S, Lammert F, Eitner F, Floege J, Ostendorf T: Complement C5 mediates experimental tubulointerstitial fibrosis. J Am Soc Nephrol 2007, 18:1508-1515.

148. Glick AD, Jacobson HR, Haralson MA: Mesangial deposition of type I collagen in human glomerulosclerosis. Hum Pathol 1992, 23:1373-1379.

149. Sampson NS, Ryan ST, Enke DA, Cosgrove D, Koteliansky V, Gotwals P: Global gene expression analysis reveals a role for the alpha 1 integrin in renal pathogenesis. J Biol Chem 2001, 276:34182-34188.

150. Zeisberg M, Ericksen MB, Hamano Y, Neilson EG, Ziyadeh F, Kalluri R: Differential expression of type IV collagen isoforms in rat glomerular endothelial and mesangial cells. Biochem Biophys Res Commun 2002, 295:401-407.

151. Schaefer L, Macakova K, Raslik I, Micegova M, Gröne HJ, Schönherr E, Robenek H, Echtermeyer FG, Grässel S, Bruckner P, Schaefer RM, lozzo RV, Kresse H: Absence of decorin adversely influences tubulointerstitial fibrosis of the obstructed kidney by enhanced apoptosis and increased inflammatory reaction. Am J Pathol 2002, 160:1181-1191.

152. Schmid H, Boucherot A, Yasuda Y, Henger A, Brunner B, Eichinger F, Nitsche A, Kiss E, Bleich M, Gröne HJ, Nelson PJ, Schlöndorff D, Cohen CD, Kretzler M, European Renal CDNA Bank (ERCB) Consortium: Modular activation of nuclear factor-kappaB transcriptional programs in human diabetic nephropathy. Diabetes 2006, 55:2993-3003.

153. Rugheimer L, Carlsson C, Johnsson C, Hansell P: Renal hyaluronan content during experimental uncontrolled diabetes in rats. J Physiol Pharmacol 2008, 59:115-128.

154. Wells AF, Larsson E, Tengblad A, Fellstrom B, Tufveson G, Klareskog L, Laurent TC: The localization of hyaluronan in normal and rejected human kidneys. Transplantation 1990, 50:240-243.

doi:10.1186/1755-1536-7-4

Cite this article as: Genovese et al:: The extracellular matrix in the kidney: a source of novel non-invasive biomarkers of kidney fibrosis? Fibrogenesis \& Tissue Repair 2014 7:4

\section{Submit your next manuscript to BioMed Central and take full advantage of:}

- Convenient online submission

- Thorough peer review

- No space constraints or color figure charges

- Immediate publication on acceptance

- Inclusion in PubMed, CAS, Scopus and Google Scholar

- Research which is freely available for redistribution 